\title{
Transfatty Acids (TFAs) in Cord Blood and Cord Tissue, in France
}

Claude Billeaud ${ }^{1}$, Nicole Combe ${ }^{2}$, Leslie Couedelo ${ }^{2}$, Wafae Belcadi ${ }^{1}$, Dominique Dallay ${ }^{3}$ Jean-Joel Leng ${ }^{3}$ and Carole Vaysse $^{1}$

1. CIC Pédiatrique, CHU Pellegrin, Université de Bordeaux, Bordeaux 33000, France

2.ITERG, Laboratoire de Nutrition Métabolisme et Santé, Université de Bordeaux, Bordeaux 33000, France

3. Services de Gynécologie-obstétrique, Maternité Pellegrin, Université de Bordeaux, Bordeaux 33000, France

\begin{abstract}
Background: Recent studies suggest that dietary transfatty acids (TFAs) at relative high levels (i) increase the risk of coronary heart disease, (ii) inhibit the metabolism of linoleic acid and consequently increase requirement for essential fatty acids (EFAs). The aim of this prospective study was to estimate TFAs the placental transfer of TFAs to the foetus cord blood and cord tissues in France. Material: TFAs consumption was measured in 59 mother-foetus couples. TFAs transferring across the placenta were estimated by comparative measurement (Capillary Gaz Chromatography) of TFAs in mother's blood lipids ( $\mathrm{n}=59$ ), cord blood lipids and cord tissue plasma lipids $(n=25)$ cord red blood tissue $(n=25)$ and umbilical vessels $(n=15)$. Results-Discussion: TFA deposition in cord blood is $0.58 \%$ slightly lower than mother level. TFAs incorporation in total lips of cord show selectivity of transfer with lower 18:1 $t$ in cord blood and preferential transfer of diene 18:2 tc in cord blood. There is competition between the 18:2 tc in cholesterol esters (CE) with the linolenic acid and a negative correlation in PLT of arterial tissues with the 18:2 tc and C20:4 n-6 or arachidonic acid (AA), then there is the same competition in PE of venous tissue. But there is no effect on growth in our population of term newborn. Conclusions: Our results confirm the placental TFAs transfer, a better incorporation in the fetus CE; we demonstrated a selective transfer for the 18:2 9 trans 12 cis $(18: 2 t c)$ and a negative correlation $(r=-0.76)$ with the linoleic acid and AA $(r=0.98)$. This competition, and the presence of these TFAs in cord tissues, even at a low TFAs consumption, remind us to be a potential risk for the fetus concerning EFA metabolism and growth.
\end{abstract}

Key Words: TFAs, pregnancy, cord blood and tissues, neonate, diet.

\section{Introduction}

Trans isomers are not synthetized by human but provided by the diet [1-11]. Trans isomers of oleic acid (trans monoenes: 18:1 t) and trans isomers of linoleic acid (trans dienes: 18:2 $t$ ) are found respectively in the fats from Ruminants (butter, milk, tallow) and in their meat, and in partially hydrogenated oils (food fats containing margarines or shortenings). Trans isomers of linolenic acid (18:3 n-3: trans trienes: 18:3 t) are formed during the deodorization of linolenic — containing oils (rapeseed, soybean) and they are also found in frying oils.

Corresponding author: Claude Billeaud, MD, MSc, Doctor ès Science, Neonatology \& Nutrition, 33000, CHU de Bordeaux, France.
Some of thesis trans isomers are shown to be converted by rats to long chain trans polyunsaturated fatty acids (PUFAs) under conditions of adequate intake of essential fatty acids (EFAs) [12]. These long chain trans PUFAs are incorporated into tissue lipids $[1,13]$. Consequently, the biological effects of both level and isomer type of dietary monoene and polyene TFAs are still being debated. The health effects of dietary trans fatty acids (TFAs) are still controversial: some, but not all, of the epidemiological and clinical studies suggested that dietary trans fatty acids at relative high levels may (i) increase the risk of cardiovascular disease in adult [1, 2], (ii) alter and inhibit the metabolism of linoleic acid (18:2 n-6) and consequently increase requirement for EFAs and eicosanoid production $[3,4,11]$. In adults, any serious 
undesirable health effect has been reported, due to the sufficient supply of linoleic acid (LA) [5-7, 11]. However, the fetus is very sensitive to factors which can interfere with the metabolism of EFAs, because of his need in long chain polyunsaturated fatty acids (LC-PUFAs) for the construction of cellular membranes in the brain; and in addition, the biosynthetic activity of LC-PUFAs is low $[12,13]$.

A study done by Koletzko [11] has reported that in premature infants, the level of plasma trans octadecenoic acid (18:1 $t)$ is inversely correlated to arachidonate levels. Moreover, an inverse correlation is also observed between trans fatty acid (TFA) level and birth weight. This suggests that exposure to high levels of TFAs during pregnancy may impair fetus growth.

The question is: do trans monoenes and trans isomers of EFA impair the metabolism of n-6 PUFA in the foetus?

The objectives of our study are firstly to compare the TFA compositions of maternal and cord blood samples and evaluate placental transfer of TFAs and secondly to study the TFAs incorporation in fetal tissues like the umbilical tissue and umbilical arterious and venous.

\section{Materials}

This is a prospective study we have been conducting, in France (in the Aquitaine region) for the previous 4 years (1996-1999), concerning trans fatty acids incorporation in France. The study was done in the following way:

We evaluated TFAs placental transfer by comparison between maternal blood and cord blood and tissues.

Peripheral vein blood and umbilical arterial were removed during abdominal (iterative caesarean surgery after normal pregnancy at full-term in PW). Cord blood (CB) was drawn by venipuncture from the placental portion of the umbilical cord immediately after its clamping. Cord tissues (CT) were collected. Blood were being kept in glass heparinized test tubes. All samples were froozen at $4{ }^{\circ} \mathrm{C}$ and then frozen and stored at $-20{ }^{\circ} \mathrm{C}$ until analysis. Total lipids were extracted from samples according to the Folch method [14]. They were separated into lipid classes by thin layer chromatography. Plasma triglycerides (TG), free fatty acids (FFA), cholesterol esters (CE) and total phospholipids (PL) were obtained using hexane/diethyl ether/acetic acid (90:10:1, v/v/v) [15]. RBC phosphatidylethanolamine (PE) and umbilical cord phosphatidylcholine (PC) and PE were separated from other lipids using chloroforme/methanol/water (65:25:4, v/v/v). Fatty acid methyl esters (FAMEs) were prepared with $14 \%$ boron trifluoride in methanol according to Morrison and Smith [15]. Analyses of FAME were carried out on a Carlo Erba 5160 chromatograph equipped with a flame-ionization detector and a split injector. A fused-silica capillary column (CP Sil 88, $50 \mathrm{~m} \times 0.25 \mathrm{~mm}$ i.e., $0.20 \square \mathrm{m}$ film; Chrompack, Middelburg, The Netherlands) was used with hydrogen as carrier gas (inlet pressure: 90 $\mathrm{kPa}$ ). The split ratio was $1 / 80$. The column temperature was programmed from 150 to $225{ }^{\circ} \mathrm{C}$ at $5{ }^{\circ} \mathrm{C} / \mathrm{min}$ and held at $225{ }^{\circ} \mathrm{C}$ until completion of the analysis. The injection port and the detector were maintained at $250{ }^{\circ} \mathrm{C}$. The different trans isomers of 18:2 and 18:3 were identified by analysis of authentic standards or well-characterized mixtures.

Results concern 59 samples of maternal and cord blood in coupled mother and newborn infant, 59 cord blood samples and finally 10 cord tissues samples.

Statistical analysis: Normality of distribution was tested by Shapiro and Wilk test. Homoscedasticity of variance was verified using the Bartlett test. The data expressed as mean \pm SD were evaluated by ANOVA and single regression. The two tailed level of significance was set at $p<0.05$. When normality was not obtained, we used Friedman test and U Man and Whitney test. The statistic software was SPSS. 


\section{Ethical Considerations}

The study protocol was approved by the local ethical review committee and informed consent was obtained from the participating.

\section{Results and Discussion}

\subsection{TFA Incorporation into Plasma}

The incorporation of TFAs is not selected regarding the different isomers because their distribution is similar to that of the diet that we determined by Combe N. \& Boue-Vaysse in adipose tissue [16] and was near $2.7 \mathrm{~g} /$ day in the diet. The TFAs level in plasma is 3 to 4 times lower than that found in AT. The trans 18:3 isomers are undetectable in blood.

The trans 18:2 isomers detected in plasma of mother are the following: 9c,12t (0.09\%), 9t,12c
$(0.04 \%)$ and the mix $9 t, 12 t / 9 c, 13 t(0.07)$ the trans monoenes, mainly $18: 1 t$ was $0.58 \%$.

\subsection{TFA Distribution in Total Lipids of Cord Plasma versus Maternal Plasma}

The results obtained of plasma samples are reported in Table 1, and Fig. 1. The TFA percentage in lipids of cord plasma is not significantly different from that found in maternal plasma: $0.76 \%$ versus $0.69 \%$ of total fatty acids respectively.

The trans isomers distribution in cord plasma lipids is different from the maternal distribution. Individual differences are remarkable regarding LA isomers particularly for the 9t12c isomer

On average, the cord plasma contains 3-times more of the 9t12c isomer than the maternal blood. Moreover, the $9 t 12 c / 9 c 12 t$ ratio is 2 in cord plasma, whereas it is

Table 1 TFAs in Total Lipids with a competition between 18:2 tc and 18:2 cc.

\begin{tabular}{|c|c|c|c|}
\hline Fatty acids \% & Mother blood LT & Cord blood LT & $p$ \\
\hline $16: 1 t$ & $0.064+/=0.0021$ & $0.051+/ \_0.037$ & $<0.0001$ \\
\hline $18: 1 t$ & $0.456+/{ }_{0} 0.129$ & $0.227+/ \_0.119$ & $<0.0001$ \\
\hline $18: 2 t t+9 c 13 t$ & $0.051+/ 0.015$ & $0.081+/ 0.034$ & $<0.0001$ \\
\hline $18: 2 c t$ & $0.059+/ \quad 0.028$ & $0.062+/ \_0.045$ & NS \\
\hline $18: 2$ tc & $0.051+/[0.022$ & $0.015+/ \quad 0.048$ & $<0.0001$ \\
\hline $18: 29 c 12 c$ & $25.348+/ 3.843$ & $10.826+/{ }^{\prime} 3.184$ & $<0.0001$ \\
\hline $18: 3$ n-3 & $0.386+/ \_0.117$ & $0.104+/ \quad 0.040$ & $<0.0001$ \\
\hline $20: 4 n-6$ & $3.308+/ 1.223$ & $11.891+/ 3.013$ & $<0.0001$ \\
\hline $22: 6 n-3$ & $2.198+/ \_0.669$ & $3.658+/ \_1.345$ & $<0.0001$ \\
\hline
\end{tabular}

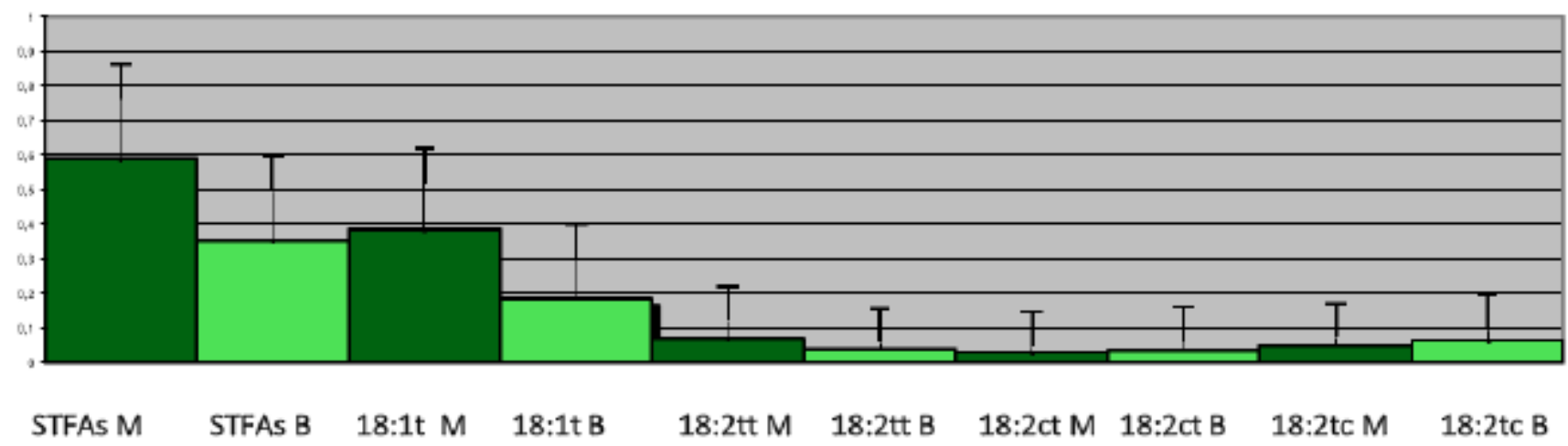

Fig. 1 Comparison Beetween TFAs Total Phospholipids Mothers (M) and Babies (B). 
0.44 in maternal plasma, similar to AT's (0.50) which reflects the diet, this trans isomer of LA might be selectively taken up from maternal circulation and transferred to the foetus. Given the prevalence of the tc isomer in cord blood, we have explored whether the tc isomer competes with the EFA form for incorporation into cord blood lipids and particularly into CE.

\subsection{Trans Isomer Distribution in Cord Blood CE vs. Maternal CE}

The TFA compositions of plasma CE (Table 2) of 25 pairs (mother-umbilical cord) are reported. The TFAs level in CE of plasma is the lowest (about $0.4 \%$ of total fatty acids) compared to total lipids (0.7\%) and AT (2.2\%). The trans 18:1 isomers are almost absent in CE (0.05\%) whereas the trans 18:2 isomers are well-incorporated (0.23\%).

These trans 18:2 isomers are incorporated into the same decreasing order in plasma and AT lipids, that is 9c, 12t $>9 t, 12 t+9 c, 13 t>9 t, 12 c$. The trans isomers of the linolenic acid (18:3 $t$ ) were undetectable.

We notice a better incorporation of total trans fatty acids in cord plasma CE $(0.87 \%)$ vs. $0.38 \%$ in maternal CE. The percentage of the 9t12c isomer in CE is significantly higher in cord $(0.28 \%)$ than in maternal plasma (0.02\%). Moreover, linear regression analysis was applied on total fatty acids in cord plasma CE $(\mathrm{n}=15)$ to evaluate the possibility interfering for incorporation into lipid classes of cord plasma between TFAs and EFAs (18:2 n-6, 18:3 n-3, long chain PUFA n-6 and n-3). We observed only one inverse correlation (Fig. 2): That was between LA and 9t12c-18:2 within CE: the correlation coefficient value was: $\mathrm{r}=-0.76(p<0.01)$ (Fig. 2$)$. We did not find any correlation between TFAs levels and birth weight or head circumference of our full-term neonates population presently (Table 3).

\subsection{Trans Isomers Distribution in Cord Tissue Lipids (CTL) and Umbilical Vessels}

We then looked at the composition of the arteries and veins and the membranes of the red blood cell of the cord in the 3 subclasses of lipids: total phospholipids, phosphatidyl-choline phosphatidyl-ethanolamine (PE) and sphingomyelin (SM).

4.5 Total Phospholipids in the Walls of the Cord ( $n=$ 30)

We investigated the TFAs incorporation into membrane phospholipids of cord blood versus maternal blood. Trans isomers percentages were determined in 59 paired samples (mother blood-cord blood-cord tissue lipids). The total TFAs level of cord lipids is on average $0.33 \%$, lower than that found in plasma (0.76\%). Apparently, there is a selective incorporation of certain isomers of TFAs into fetal tissue as well as into fetal plasma lipids higher 18:2 tt $+18: 2$ 9c 13t, but lower 18:2 tc.

The predominance of the $18: 2$ tc isomer is no longer found in the parietal tissues of the cord.

Table 2 Comparison of TFAs of plasmatic cholesterol ester (CE) between mother and cord blood plasma.

\begin{tabular}{|c|c|c|c|}
\hline $16: 1 t$ & $0.013+/[0.0024$ & $0.111+/[0.062$ & $<0.0001$ \\
\hline $18: 1 t$ & $0.058+/ \_0.061$ & $0.166+/[0.109$ & $<0.0001$ \\
\hline $18: 2 t t+9 c 13 t$ & $0.008+/[0.021$ & $0.101+/ \_0.047$ & $<0.0001$ \\
\hline $18: 2 c t$ & $0.08+/=0.025$ & $0.125+/[0.049$ & $<0.0001$ \\
\hline $18: 2$ tc & $0.032+/ 0.023$ & $0.211+/ 0.084$ & $<0.0001$ \\
\hline $18: 2$ 9c12c & $31.188+/ 8.697$ & $17.854+/ 3.117$ & $<0.0001$ \\
\hline $18: 3 n-3$ & $0.483+/ \_0.200$ & $0.109+/[0.088$ & $<0.0001$ \\
\hline $20: 4 n-6$ & $6.971+/ 1.732$ & $14.419+/ 4.419$ & $<0.0001$ \\
\hline $22: 6 n-3$ & $0.785+/ \_0.280$ & $1.296+/ \_0.728$ & $<0.0001$ \\
\hline
\end{tabular}




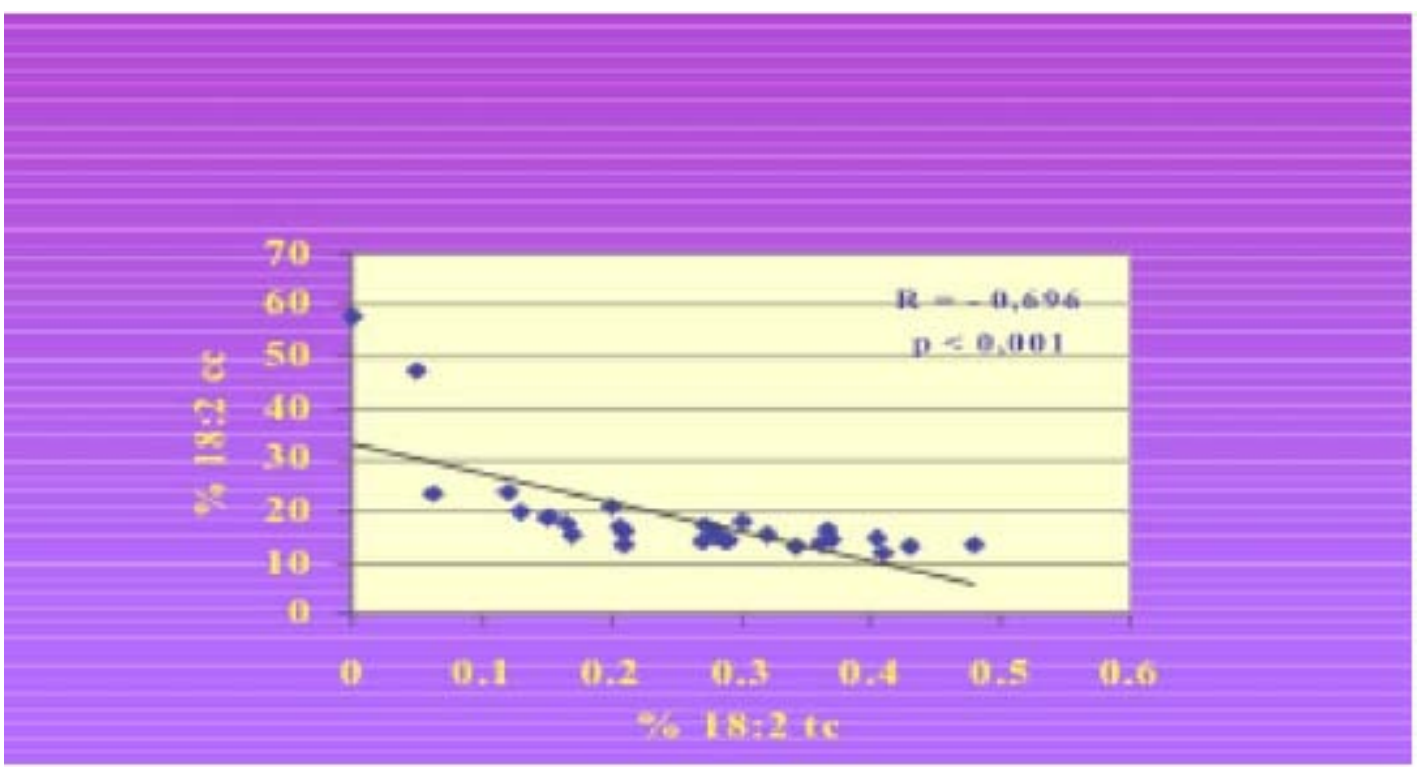

Fig. 2 Inverse correlation between linoleic acid and 18:2 tc in CE.

Table 3 Interaction between TFAs and EFAs and growth in the literature.

\begin{tabular}{|c|c|c|c|c|}
\hline Authors & TFAs type & Class of lipids & EFA & Growth \\
\hline $\begin{array}{l}\text { Koletzko } \\
1992\end{array}$ & $\begin{array}{l}18: 1 \mathrm{t} \\
\text { TFAs }\end{array}$ & Tryglicerides & LC-PUFA & $\begin{array}{l}\text { Negative correlation } \\
\text { growth and TFAs }\end{array}$ \\
\hline $\begin{array}{l}\text { Ayyagary } \\
1996\end{array}$ & $18: 1 \mathrm{t}$ & Triglycerides & $22: 6 n-3$ & No effect on growth \\
\hline $\begin{array}{l}\text { Decsi } \\
1995 \\
1-15 \text { years old }\end{array}$ & $\begin{array}{l}18: 1 \mathrm{t} \\
\text { TFAs }\end{array}$ & Phospholipids & $20: 4 n-6$ & No effect on growth \\
\hline Van Houwellingen & TFAs & Cord Vessels & & $\begin{array}{l}\text { Negative correlation } \\
\text { growth and TFAs }\end{array}$ \\
\hline Our Results & $18: 2$ tc & $\begin{array}{l}\text { CE } \\
\text { PLT, PC of Cord Vessels }\end{array}$ & $\begin{array}{l}18: 2 n-6 \\
20: 4 n-6\end{array}$ & No effect on growth \\
\hline
\end{tabular}

In the venous walls $(\mathrm{n}=15)$. All isomers combining TFAs represent $0.24 \%$. The predominant isomer is always 18:1 $t(0.11 \%)$. The other isomers are in order of decreasing the 18:2 $t t+189 \mathrm{c} 13 \mathrm{t}(0.09 \%), 18: 2 \mathrm{ct}$ $(0.04 \%)$ the $18: 2$ tc $(0.02 \%)$.

While the plasma contains as much as $18: 2$ tc as 18:1 $t$, the phospolipids of the venous walls incorporate 6 times less. We do not observe a negative correlation between AGE and AGT.

In the arterial TFAs represents approximately $0.36 \%$ of total FA. As for the vein, the predominant isomers are 18:2 $t+9 \mathrm{c} 13 \mathrm{t}$ 18:1 $t$ followed by 18:2 $t c$ and $18: 2 c t$, respectively equal to $0.17 \%, 0.12 \%$, $0.05 \%, 0.02 \%$.

There is a negative correlation between the 18: $t c$ and the linoleic acid $(\mathrm{r}=0.91)$ in the PLT of the cord arteries, but also a strong positive correlation between the 18:2 tc and the 20:3 n-9 marker of an EFA deficit. Finally, we note a negative correlation drill $(r=0.78)$. We thus see that the trans dienes and particularly the 18:2 tc interferes with the metabolism of linoleic acid. (Fig. 2). However, we do not observe as Koletzko [17, 21] correlation between 18:1 $t$ and TFAs (Table 2). TFAs represent on average $0.20 \%$ of the total fatty acids and the predominant isomer is the $18: 1(0.14 \%)$ isomers. Compared to venous plasma, GR incorporates less TFAs. In all cases the 18:3 $t$ remains undetectable.

In sum, there are differences in TFAs composition between afferent vessels of the fetus (vein) and 
associated vessels (arteries). On average, the PUFA content of the n-9 series is higher in the PLT of the arteries. The opposite is true for the n-9 series.

The fact that the arteries contain more than the veins could testify a very active desaturase activity in the efferent vessels. Indeed, the 20:4 n-6/18: n-6 ratios are higher than in the vein as the ratio $20: 3 \mathrm{n}-9 / 18$ : 3n-9.

This aspect seems to confirm the very important need for the long-chain PUFA of the fetus. It is conceivable that any compound inhibiting this synthesis could have adverse effects.

\subsection{Phophatidyl Choline}

\subsubsection{Parietal Cord Weave}

In PCs there is a larger amount of the mixture 18:2 $t t+18: 2$ 9c 13t. As well in the PLT as in the PC of the walls of the cord one detects of negative correlation between AGT and AGE.

4.6.2 Venous Walls of the Cord $(n=7)$

The sum of the TFAs represents $0.39 \%$ of the total fatty acids. The major isomers are 18:1 $t$ (0.15\%), $18: 2 t t+18: 2$ 9c $13 t(0.13 \%)$ followed by $18: 2 t c$ (0.05\%) and 18: $c t(0.02 \%)$. As in the PLT of the arterial walls, negative correlations were found between 18:2 $c t$ and arachidonic acid (AA) ( $\mathrm{r}=0.98$, $p<0.001$ ) and 20:4 n-6/18:2 n-6. There is therefore competition between the 18:2 $c t$ and the EFAs and not a competition with the 18:1 trans as Koletzko [17] had found. Although the rate of 18: $t$ is low, we think it is important to emphasize this correlation which could reflect the isomers of linoleic acid isomers to interfere with the conversion of the latter to 20:4 n-6, with potential repercussions on prostaglandin synthesis as discussed since PC is a reserve of 20:4 n-6, precursor of prostaglandins.

4.6.3 Arterial Walls $(\mathrm{n}=15)$

Total TFAs represent on average $0.6 \%$ of total fatty acids. The majority isomer is the $18: 2 t t+18: 29 \mathrm{c} 13 \mathrm{t}$ (0.3\%) followed by $18: 1 t(0.16 \%)$ and the $18: 2 t c$ $(0.1 \%)$ and the $18: 2$ tc and $16: 1 t$ are very low, respectively $0.03 \%$ and $0.02 \%$ of the total fatty acids. The fact that there are more TFAs in the artery than in the vein may raise the question of relative accumulation in the fetus.

4.6.4 Venous Blood GR $(\mathrm{n}=11)$

Total TFAs represent approximately $0.22 \%$ of total fatty acids. The majority isomers are 18:1 $t(0.1 \%)$ and 18:2 tc (0.06\%). The 16:1 t, 18:2 tt + 18:2 9c13t and the $18: 2 c t$ are in equal proportion $(0.03 \%)$.

\subsection{Phosphatidylethanolamine (PE)}

4.7.1 Venous Walls $(\mathrm{n}=10)$

All AGTs represent $0.27 \%$ of total GAs. The predominant isomers are $18: 1 t(0.09 \%) 16: 1 \mathrm{t}(0.07 \%)$ and 18:2 $t t+18: 2$ 9c 13t (0.07\%) acids. The 18:2 ct isomer is $0.03 \%$ and the $18: 2$ tc is substantially non-existent. It is noted that half of the GAs of the PE are PUFAs. As expected the proportion of n-3 PUFAs is higher than in the PC (8.98\% vs. $1.94 \%)$. No negative correlation was observed between TFAs nor with the 20:4 n-6 isomer or 22:6 n-3 fatty acids essential for the development of the nervous system of the fetus.

4.7.2 Arterial Walls $(\mathrm{n}=10)$

Total TFAs represent $0.39 \%$ of total FAs. As for the vein, the major isomers are 18:2 $t t+18: 2$ 9c $13 t$ (0.12\%), 16:1 $t(0.11 \%)$ and $18: 1 t(0.09 \%)$. The acids $18: 2$ ct and 18:2 tc respectively represent $0.05 \%$ and $0.03 \%$. No negative correlation between AGT and AGE is observed. On the other hand, there is a positive correlation between 18:2 tc and 20:3 n-9 (classical marker of EFA deficiency).

\subsubsection{Venous Blood RBC Walls}

The average total AGT is $0.24 \%$. Only the $18: 1 t$ isomers $(0.12 \%)$ predominate unlike the cord vessels. The 18: $t c, 18: 2 c t, 18: 2 t t$ and 16:1 isomers represent only $0.04 \%, 0.03 \%, 0.03 \%$ and $0.02 \%$. Overall, PE has a lower proportion of TFA than PC

\subsection{Sphingomyelines}

Whatever the compartments: Arteries, Veins, GR 
the incorporation of AGT in sphingomyelin is almost nil. The only fraction that is incorporated into the PCs is the 18:2 (9c $12 \mathrm{t}$ ) isomer which is incorporated by the SM as 18:1 (9c) as if the 12t bond did not exist. It may therefore be thought that this phospholipid characteristic of the membranes of the nervous system protects against the possible effects of TFAs.

In total the various trans isomers are found in RBC, vein, and cord arteries. The proportions of the different isomers are identical except for the 18:2 tt + 18:2 9c12t isomer which predominates in the arteries.

The 18:2 major tc isomer in cord plasma does not concentrate in the tissues of the vessels.

The vessels and more precisely the arteries privileged the mixture 18:2 $\mathrm{tt}+18: 2$ 9c13t.

The content of TFAs in plasma phospholipids in healthy children was inversely correlated with AA, total n-6 long chain PUFAs and the ratio of arachidonic and linoleic acids, suggesting that TFAs interfere with linoleic acid metabolism [17]. Generally, these effects are not observed in adult subjects due to the fact that linoleic acid is more than sufficiently present in a normal diet, although production of some eicosanoids may be implicated. On the other hand, effects on the fetus may be amplified, due to extensive need for AA and docosahexaenoic acid (DHA) in preterm infants [18]. Because of this, the fetus is very sensitive to factors which can interfere with the metabolism of EFA. A study done by Koletzko et al. [11] has reported that in premature infants, the level of plasma 18:1 $\mathrm{t}$ is inversely correlated to long chain PUFA levels. An inverse correlation is also observed between TFAs level and birth weight. Consequently, the biological effects of both level and isomer type of dietary monoene and polyene TFAs are still being debated. The aim of this prospective study was to estimate the placental transfer of TFAs to the foetus. These trans isomers cannot be synthesized by humans, thus they must be derived from dietary sources. Monoenes and dienes TFA are a side product of catalytic hydrogenation of vegetable oils and bacterial biohydrogenation in the rumen of animals (dairy products), and are found respectively in the fats of ruminants and in partially hydrogenated oils.

In mothers plasma, on the average, the TFAs level is about $0.6 \%$ of total fatty acids. This is three to four times lower than in adipose tissue [18]. The proportion of trans monoenes is much lower in plasma. The situation however, is not the same for the dienes. Their relative percentages in plasma are different from those found in adipose tissue. We see that the ratio of $18: 2$ trans to $18: 1$ trans is two times higher in plasma than in adipose tissue. This could reflect the known influence of metabolism on the incorporation of TFAs into different lipid classes of blood. The 18:3 isomers are undetectable in blood.

The incorporation of these different isomers in the $\mathrm{CE}$ has been researched because of the important role they play in the transport of PUFA.

We note that the 18:1 trans is almost absent in CE, whereas the 18:2 isomers are well-incorporated. It is well known that the trans 18:1 is preferentially incorporated into the sn1 position of phosphatidylcholine and the 18:2 in sn2 position [7, 19]. The $t$ 18:2 are incorporated in the same decreasing order in the 2 lipid samples, like in adipose tissue, that is ct $>$ the mix $>$ tc.

We have noted that all classes of TFAs are found in our samples of pregnant women. Therefore, we have been interested in comparing this isomer profile with that found in umbilical cord blood in order to explore the placental passage of these TFA isomers.

Our results showed that the level of total TFAs, found in cord blood, is not significantly different from that found in the adult samples. However, if we compare the 18:2 profiles of the 2 groups, significant differences appear between: on the average, the umbilical cord blood contains 3 times more of the $t c$ than the maternal blood. Because of the prevalence of the $t c$ isomer in cord blood, we have explored whether the $t c$ isomer is in competition with the EFA form for incorporation into cord blood lipids. It is known that 
the development of the fetus depends on EFAs, supplied by the mother: in particular, on maternal triglycerides. The fatty acids pass through the placental membrane in the form of free fatty acids. We notice that there is a preferential incorporation of the 9t 12c isomer. This observation may be explained by the following hypothesis: either selective placental uptake from maternal TG or slower removal from cord blood is possible explanations for the higher level of tc 18:2. The behavior of diene structures can be explained by differences in metabolic utilization. It is known that the 9t 12c isomer is metabolized much more slowly in the synthesis of long chain PUFA than the linoleic acid and the 9c 12t isomer [7, 19, 22], so, 18:2 tc could be slowly removed from cord blood and be accumulated.

In light of the prevalence of the 9t 12c isomer, we have been interested in studying the distribution of the isomer in the different lipid classes in order to see where it is most incorporated. The incorporation of the 9t 12c isomer is higher in the CE than in total lipids. Since the preferential incorporation of this isomer, on the sn2 position of the tissue, phosphatidylcholine (PC) $[17,19]$ has been observed, we can postulate that this is true as well for the cord plasma PC. This would explain the preferential incorporation of this trans diene into the $\mathrm{CE}$, since they are normally synthesized using fatty acids taken from the sn2 position of PC by LCAT. Our data do not agree with the work reported by Koletzko [17, 20] who demonstrated a negative correlation between trans 18:1 t, arachidonate and fetus growth.

But, we did not observe in our full-term population any relation between TFAs level and birth-weight or head circumference presently (Table 3). The main difference between German and French study was certainly the higher exposure to TFAs, with cord blood TFAs levels (1.66\% vs. $69 \%$ )

Houwelingen [19] demonstrated that the content of the TFAs in human fetal tissue and umbilical venous walls from full term neonates was inversely correlated with the n-6 long chain PUFA and docosahexaenoic acid; an inverse correlation between TFAs content in umbilical venous walls and birth weight in full term neonates was also observed. We found in the cord PE a lower proportion of monoenes and a higher proportion of the diene tc than that found in maternal PE. This is in accord with our findings in plasma lipids with regard to the differences observed in maternal and cord plasma. Apparently, there is a selective incorporation in fetal cord tissue of certain isomers of TFAs in membrane as well as in plasma. Any conclusive interpretation would have to be made on a larger sample.

\section{Conclusion}

Major dietary source of TFAs in France comes mainly from dairy fats (60\%) and only $40 \%$ from hydrogenated fats. However, margarines tend to a very low level of TFAs. Pregnancy did not modify consumption and incorporation of TFAs in blood or adipose tissues. In mother's blood, TFA level was $0.6 \%$ of total fatty acids: monoene level was $0.4 \%$, dienes $0.2 \%$ and trienes was undetectable. Overall results confirm thus that the trans isomers of LA, present in maternal blood can also be found in umbilical cord blood. The trans 18:2 isomers represent $0.3 \%$ of the total fatty acids. The trans $18: 3$ isomers are undetectable. We observed that one of the trans isomers of LA was preferentially incorporated into the cord blood, that was the 9t12c-18:2, and there was an inverse correlation between levels of 9t12c-18:2 and LA in CE. These data and the occurrence of the other trans isomers of LA in cord blood raise the question about their possible implication in developmental failure of the fetus, as suggested [9, 2]. Indeed, trans isomers of LA can be converted into trans isomers of AA. At this time, very little is known about their metabolic fate. However, recent studies have shown that they affect platelet function and arachidonic acid metabolism differently than their cis homologues. These data underline the 
necessity to give dietetic advice to pregnant women to choose their fat intake and particularly to cover adequate requirement for the essential fatty acids 18:2 n-6 and 18:2 n-3 and DHA 350 mg/d.

Since this study we controlled the TFAs level in the Human Milk which is correlated to food TFAs intake and from this study (1996-99) the level of TFAs decrease $2.1 \%$ (1997) to $0.83 \%$ (2012) and $1 \%$ (2014) $[23,30]$. This decrease is linked to excellent cooperation between scientists and margarine and oil industry in France.

\section{Acknowledgements}

We thank the participating mothers and the staff of the obstetrical units, Mrs L. Fonseca and Mrs P. Nonatel for their technical assistance, Mrs M. N. Roturier for the diet record processing. This study was in part financially supported by French bodies: CSM (Chambre Syndicale de la Margarinerie), SGFHTF (Syndicat Général des Fabricants d'Huiles et de Tourteaux de France), Terra Univia, and SIDO (Sté Interprofessionnelle Des Oléagineux-Protéagineux).

\section{References}

[1] Entressangles, B. 1995. "Isomères Trans. D’acides Gras Insaturés: Aspects métaboliques et nutritionnels.” O. C. L. 2: 162-9.

[2] Mensink, R. P., and Katan, M. B. 1990. "Effect of Dietary Trans Fatty Acids on High-Density and Low Density Lipoprotein Cholesterol Levels in Healthy Subjects.” News Engl. J. Med. 323: 439.

[3] Wolff, R. L. "Trans Polyunsaturated Fatty Acids in French Edible Rapeseed and Soybean Oils.” J. Am. Oil Chem. Soc. 69: 106-10.

[4] Sébédio, J. L., Grandgirard, A., and Prevost, J. 1988. "Linoleic Acid Isomers in Heat Treated Sunflower Oils." J. Am. Oil Chem. Soc. 65: 362-6.

[5] Chardigny, J. M., Sébédio, J. L., Juaneda, P., Vatèle, J. M., and Grandgirard, A. 1995. "Effects of Trans n-3 Polyunsaturated Fatty Acids on Human Platelet Aggregation.” Nutr. Res. 15: 1463-71.

[6] Willet W., Stampfer M. J., and Manson J. E. 1993. "Intake of Trans-Fatty Acids and Risk of Coronary Heart Disease among Women.” Lancet 341: 581-5.

[7] Berdeaux, O., Chardigny, J. M., Sébédio, J. L., Mairot, T., Poullain, D., Vatèle, J. M., and Noël, J. P. 1996. “Effects of a Trans Isomer of Arachidonic Acid on Rat Platelet Aggregation and Eicosanoid Production.” J. Lipid Res. 37: 2244-50.

[8] Combe, N. 1996. Oils \& Fats. pp. 652-62, Paris: Lavoisier Ed.

[9] Sugano, M., and Ikeda, I. 1996. "Metabolic Interactions between Essential and Trans Fatty Acids.” Curr. Opin. Lipidology 7: 38-42.

[10] Kuhn, D. C., and Crawford, M. 1986. "Placental Essential Fatty Acid Transport and Prostaglandin Synthesis.” Prog. Lipid Res. 25: 345-53.

[11] Koletzko, B. 1992. "Trans Fatty Acids may Impair Biosynthesis of Long-Chain Polyunsaturates and Growth in Man.” Acta Paediatr 81: 302-6.

[12] Ratnayake, W. M. N., Chen, Z. Y., Pelletier, G., and Weber, D. 1994. "Occurrence of 5c, 8c, 11c, 15t Eicosatetraenoic Acid and Other Unusual Polyunsaturated Fatty Acids in Rat Fed Partially Hydrogenated Canola Oil.” Lipids 29: 707-14.

[13] Beyers, E. C., and Emken, E. A. 1991. "Metabolites of Cis Trans and Trans Cis Isomers of Linoleic Acid in Mice and Incorporation into Tissue Lipids.” Biochim. Biophys. Acta 1082: 275-84.

[14] Folch, J., Lees, M., and Sloane-Stanley, G. H. 1957. “A Simple Method for the Isolation and Purification of Total Lipids from Animal Tissues.” J. Biol. Chem. 226: 497-509.

[15] Morrison, W. R., and Smith, L. M. 1964. "Preparation of Fatty Acid Methyl Esters and Dimethylacatals from Lipids with Boron Fluoride-Methanol.” J. Lipid. Res. 5: 600-8.

[16] Boue-Vaysse C., Combe, N., Billeaud, C., Mignerot, C., Entressangles, B., and Thery, G. 2000. "Trans Fatty Acids in Adipose Tissue of French Women in Relation to Their Dietary Sources.” Lipids 35 (5): 561-72.

[17] Koletzko, B., and Müller, J. 1990. "Cis- and Trans- Isomeric Fatty Acids in Plasma Lipids of Newborn Infants and Their Mothers.” Biol. Neonate. 57: 172-8.

[18] Decsi, T., and Koletzko, B. 1995. "Do Trans Fatty Acids Impair Linoleic Acid Metabolism in Children?” Ann. Nutr. Metab 39: 36-41.

[19] Houwelingen, A. C., and Hornstra, G. 1994. "Trans Fatty Acids in Early Human Development in Fatty Acids and Lipids: Biological Aspects.” World Rev. Nutr. Diet. vol 75. Edited by A. P. Simopoulos, and E. Tremoli. Basel: Karger, 75-178.

[20] Koletzko, B., and Müller, J. 1990. "Cis- and TransIsomeric Fatty Acids in Plasma Lipids of Newborn Infants and Their Mothers.” Biol. Neonate. 57: 172-8.

[21] Carlson, S. E., Clandinin, M. T., Cook, H. W., Emken, E. A., and Filer, L. J. 1997. "Trans Fatty Acids: Infant and 
Fetal Development.” Am. J. Clin. Nutr. 66: 717-36.

[22] Privett, O. S., Stearns, E. M., and Nickell, E. C. 1967. "Metabolism of the Geometric Isomers of Linoleic Acid in the Rat.” J. Nutr. 92: 303-10.

[23] Vaysse, C., Billeaud, C., Guesnet, P., Couedelo, L., Alessandri, J. M., Putet, G., and Combe, N. 2011. "Teneurs en Acides Gras Polyinsaturés Essentiels du Lait Maternel en France: Evolution des Teneurs en Acides Linoléique et Alpha-Linolénique.” Médecine \& Nutrition 47 (2): 5-9.

[24] Mazurier, E., Rigourd, V., Perez, P., Buffin, R., Couedelo, L., Vaysse, C., Belcadi, W., Sitta, R., Nacka, F., Lamireau, D., Cambonie,G., Picaud, J. C., and Billeaud, C. 2017. "Effects of Maternal Supplementation with Omega-3 Precursors on Human Milk Composition.” Journal of Human Lactation 33 (2): 319-28.

[25] Billeaud, C., Bouglé, D., Sarda, P., Combe, N., Mazette, S., Babin, F., Entressangles, B., Descomps, B., Nouvelot, A., and Mendy, F. 1997. "Effects of Preterm Infant Formula Supplementation with Linolenic Acid with a
Linoleate/Alpha-Linolenate Ratio of 6: A Multicentric Study.” Eur. J. Clin. Nutr. 51: 520-26.

[26] Craigh-Schmidt, M. C., Weete, J. D., Faircloth, S. A., Wickwire, M. A., and Livant, E. J. 1984. "The Effects of Hydrogenated Fat in the Diet of Nursing Mothers on Lipid Composition and Prostaglandin Content of Human Milk.” Am. J. Clin. Nutr. 39: 778-86.

[27] Boatella, J., Rafecas, M., Codony, R., Gilbert, A., Rivero, M., and Tormo, R. 1993. "Trans Fatty Acid Content of Human Milk in Spain.” J. Pediatr. Gastroenterol. Nutr. 16: 432-4.

[28] Chen, Z. Y., Pelletier, G., Hollywood, R., and Ratnayake, W. M. N. 1995. “Trans Fatty Acids in Canadian Human Milk.” Lipids 30: 15-21.

[29] Wolff, R., L. 1994. "Les Isomères 18:1 Trans Dans l'Alimentation des Européens. Evaluations Quantitatives et Qualitatives.” O. C. L. 1: 209-18.

[30] Emken, E. A. 1981. "Metabolic Aspects of Positional Monounsaturated Fatty Acids Isomers.” J. Am. Oil. Chem. Soc. 58: 278-83. 